\title{
Editorial
}

Gynecologic and

Obstetric Investigation

Published online: November 7, 2012

DOI: $\underline{10.1159 / 000343105}$

\section{Human Reproduction Program: The First Partnership for Health and Development at the WHO}

Union gives strength. Aesop (620 BC to $560 \mathrm{BC}$ )

\section{Establishing the Special Program and Its Governance Arrangements}

It is somewhat surprising and, in retrospect, quite encouraging that the first global partnership for health and development was established on the politically sensitive topic of human reproduction. The UNDP/UNFPA/ WHO/World Bank Special Programme of Research, Development and Research Training in Human Reproduction (HRP) established in 1972 by a World Health Assembly Resolution has a mandate for '... promoting scientific and technical cooperation between developed and developing countries' and 'coordinating the global research efforts in the field of reproductive health' [1].

The governance arrangements of this special program were very innovative for the early seventies, building on the participation and contribution of many actors to advance the reproductive health agenda. They became a model for the subsequent partnerships, including the Tropical Disease Research program established in 1975. The innovations included co-sponsorship from among the United Nations (UN) Specialized Agencies and Pro- grams that shared the commitment to promoting reproductive health, a joint policy coordination committee, with representation of governments from the North and the South, and a technical advisory group. The HRP Secretariat was established in the World Health Organization (WHO) and, administratively, is the research arm of the WHO Department of Reproductive Health and Research (RHR). Successive independent evaluations of HRP found its governance arrangements to contribute significantly to its program results because they built ownership by all stakeholders and broad technical and political support for HRP. In addition, hosting by the WHO was found useful because research findings have been distributed through WHO channels and have benefited from the WHO's own credibility $[2,3]$.

Since its establishment 40 years ago, HRP has served as the leader in the UN system for research in human reproduction [4]. It has brought together 'policy makers, scientists, health care providers, and community representatives to identify and address priorities to improve sexual and reproductive health'. In its relationship with the WHO's RHR, the partnership has, for many years, played a prominent role in assisting countries to achieve their country-specific goals in sexual and reproductive health and rights.

\section{KARGER}

Fax +4161306 1234

E-Mail karger@karger.ch

www.karger.com
(C) 2012 S. Karger AG, Basel

0378-7346/12/0743-0181\$38.00/0

Accessible online at: www.karger.com/goi 
The RHR has been greatly enhanced by the solid global research program and research capacity strengthening to which HRP has contributed. It is today one of the most effective development programs related to reproductive health. Its strength is found in the manner of how it facilitates a continuum ranging from generating research evidence to synthesis of this evidence into guidelines and to the translation of these guidelines into strengthening policy formulation and programming.

The match with the WHO has been beneficial for accomplishing both the WHO's mandate and that of other entities concerned with reproductive health. The WHO's vision statement is 'the attainment by all peoples of the highest possible level of sexual and reproductive health. It strives for a world where all women's and men's rights to enjoy sexual and reproductive health are promoted and protected, and all women and men, including adolescents and those who are underserved and marginalized, have access to sexual and reproductive health information and services' [5].

Countries around the world have also responded with expressions of commitment to improving the sexual and reproductive lives of their citizens. This response, for example, is demonstrated in the text of the Programme of Action of the International Conference on Population and Development (Cairo, 1994) and the Beijing Declaration and Platform for Action of the Fourth World Conference on Women (Beijing, 1995). Both of these documents were adopted by the consensus of the international community represented at the most senior levels. States reaffirmed their commitment again by adopting the global reproductive health strategy to accelerate progress towards the attainment of international goals and targets at the World Health Assembly in 2004 [6]. More recently, in September 2010, the UN SecretaryGeneral launched a Global Strategy for Women's and Children's Health, which called for universal access to essential health services further underscoring the importance of global efforts to improve sexual and reproductive health [7].

\section{HRP Functions}

HRP promotes, conducts, and synthesizes evidence needed on the role of sexual and reproductive health in sustainable development around these five components of the WHO Global Reproductive Health Strategy:

- improving antenatal, perinatal, postpartum, and newborn care;
- providing high-quality services for family planning, including infertility services;

- eliminating unsafe abortion;

- combating sexually transmitted infections (STIs), including HIV, reproductive tract infections, cervical cancer, and other sexual and reproductive health morbidities;

- promoting sexual health, with gender, reproductive rights, and adolescents, as cross-cutting.

The strategy also outlines actions needed to accelerate progress towards the attainment of the Millennium Development Goals (MDGs) and other international goals and targets, and calls for action in five key areas:

- strengthening health systems capacity;

- improving information for priority setting;

- mobilizing political will;

- creating supportive legislative and regulatory frameworks;

- strengthening monitoring, evaluation, and accountability.

HRP's work is premised on the need to achieve access to and quality of sexual and reproductive health care in order to meet the needs of diverse populations, particularly the most vulnerable. Three overarching themes form part of the mission of RHR's work: universal access to sexual and reproductive health including addressing unmet needs; the renewal of primary health care, and fostering programmatic and policy linkages between services and interventions for HIV and for sexual and reproductive health. The strategy and a framework for its implementation are targeted at a wide range of policy makers in governments, international agencies, professional associations, NGOs, and other institutions.

\section{Key Research Achievements}

In the field of improving antenatal, perinatal, postpartum, and newborn care, HRP has conducted many significant studies to find definite interventions on preventing and managing hypertensive complications during pregnancy using magnesium sulfate, and on management of postpartum hemorrhage, two of the most severe causes of maternal morbidity and mortality. Studies are underway looking at the development of innovative technologies for low-cost safe delivery during prolonged labor.

HRP has led, conducted, and coordinated a large number of multicenter trials on the safety and efficacy of a variety of contraceptive methods, providing important tools and conclusive evidence that contribute significant- 
ly to the prevention of unplanned pregnancies. With the goal of expanding contraceptive choice, HRP has contributed to the development of new methods of contraception such as the vaginal ring, the monthly hormonal injectable contraceptive, proof of concept for a male hormonal contraceptive, and emergency contraception regimens.

It develops and disseminates evidence-based family planning guidelines and tools that have been globally used for programmatic and clinical guidance for over a decade. These and its various versions, including the MEC wheel, a derivative of the award-winning WHO Medical Eligibility Criteria for Contraceptive Use, remain among the most long-standing and flagship achievements for their impact on the lives of women and their families, thus reducing the problems related to unplanned or unwanted pregnancies.

HRP plays a leading role among the UN agencies in preventing unsafe abortion and related mortality. Studies on safe and effective medical abortion regimens for the first trimester (comprising mifepristone and misoprostol) were conducted by HRP. The new WHO/HRP safe abortion technical and policy guidelines serve as a reference document for UN organizations, NGOs, professional associations, program managers, and health care providers. These guidelines and research findings markedly reduce the problems related to unsafe abortion practices.

The Kesho Bora study (or a 'better future' in Swahili) was a study to reduce mother-to-child transmission of HIV led by HRP. It found that giving mothers with HIV a combination of antiretroviral medications during pregnancy, delivery, and breastfeeding reduced transmission to infants by $43 \%$ compared with the standard WHO recommendations at the time of the study. HRP leads the Global Elimination of Congenital Syphilis Initiative to highlight the importance of congenital syphilis as a key issue for maternal and newborn health, with screening to strengthen underlying antenatal care systems and in HIV settings. HRP has also assessed the acceptability and feasibility of implementing a cervical cancer prevention program based on a 'see and treat' approach using visual inspection with acetic acid and cryotherapy [5].

HRP has also undertaken landmark studies on the health consequences of female genital mutilation on girls and future pregnancies, deliveries, and infants, which led to policies restricting the practice in many countries. HRP has worked on global research to document how human rights standards have been specifically applied to sexual health and sexuality in international, regional, and national laws and jurisprudence as a basis for developing international standards. An HRP systematic review of risk-taking behaviors among adolescents in developing countries found that adolescents were generally poorly informed about ways to prevent such unwanted outcomes as STIs and pregnancy [5].

\section{Capacity for Research and Program Development}

A major area of work in HRP is on capacity strengthening for research and program development for lowand medium-income countries. Strengthening research capacity in low- and middle-income countries to improve sexual and reproductive health has contributed in many diverse ways towards accelerating the achievement of universal access to sexual and reproductive health. A recent initiative involved mobilizing academic and research institutions towards the generation of evidence to operationalize the research aspects of the UN Secretary-General's Global Strategy for Women's and Children's Health.

HRP also contributes to developing and issuing various global estimates on the magnitude, trends, and causes of maternal mortality, unsafe abortion, and STIs, which guide countries and programs in the various health plans and implementation of interventions to address these problems.

\section{The Future Direction}

The WHO regards access to sexual and reproductive health services as the fundamental right of every woman and a critical component of universal health coverage. Hand in hand with this right, there is a need to honor the dignity of women by giving them a range of family planning options and the freedom to make their own choices. However, this right is far from being fulfilled. Maternal mortality remains high in many countries. Worldwide, an estimated 222 million women have an unmet need for contraception. In many countries, more than $30 \%$ of women who want to use contraception are unable to get it. This translates into an unacceptably high number of unintended pregnancies and unsafe abortion practices and all the risks they bring. The job for HRP is far from completed and requires an accelerated response.

This month, Prof. Marleen Temmerman will take over the helm of HRP. For the first time, HRP will be led by a woman. Prof. Temmerman brings to HRP global recognized expertise in gynecology and obstetrics. Her im- 
pressive research record and significant experience as a parliamentarian in her home country of Belgium situate her ideally to lead HRP to new heights. The challenges she will initially take on include developing a new WHO and global strategy for reproductive health, leadership of the ICPD at 20, and development of the post-2015 MDG health and development agenda and goals. Most importantly, she will be able to apply the lessons learned from the first 40 years of HRP to this work. She will also have the experience as the head of a WHO collaborating center with a tradition of research and innovation. These talents will be crucial to expanding the partnerships that have served human reproduction so well and which can be ap- plied to tackling new challenges, including assisted reproduction, infertility, and the emergence of reproductive tract cancers such as cervical and breast cancers that are leading causes of death for women.

Reproductive health is more important today than ever before, in large part because of HRP and the strong cooperative leadership it has had for more than 40 years. Its example of leadership through partnership and cooperation is as necessary and constructive today as it was innovative 40 years ago. We have a model that works; we now need to push it to new heights to secure reproductive health for all.

\section{References}

$\checkmark 1$ Mbizvo MT, d’Arcangues C, Van Look PF, Benagiano G: 40 years of innovation in sexual and reproductive health. Lancet 2012; 380:705-706.

2 UNDP/UNFPA/WHO/World Bank Special Programme of Research, Development and Research Training in Human Reproduction: External evaluation 1990-2002. Geneva, WHO, 2003.
3 External evaluation 2003-2007: follow-up on governance, management, administration and efficiency - a case study. UNDP/ UNFPA/WHO/World Bank Special Programme of Research, Development and Research Training in Human Reproduction.

4 HRP at 40: what they say (a history of scientific achievement to advance sexual and reproductive health). http://www.who.int/reproductivehealth/publications/reports/rhr hrp_12_06/en/.

5 WHO's strategic vision in sexual and reproductive health and rights: business plan 2010-2015. http://www.who.int/reproductivehealth/governance/en/.
6 Reproductive health strategy to accelerate progress towards the attainment of international development goals and targets: global strategy adopted by the 57th World Health Assembly. http://www.who.int/reproductivehealth/publications/general/RHR_04_8/ en/index.html.

7 UN Secretary General Global Strategy for Women's and Children's Health http://www. who.int/hrp/maternal_child_health_strategy/en/. 